\title{
Modeling Impact of Economic Status on Body Mass Index among Women of Reproductive Age in Nigeria: Using Analysis of Covariance (ANCOVA)
}

\author{
Michael Ekholuenetale ${ }^{1}$, Kelly Relobhegbe Okhae ${ }^{2}$, Godson Tudeme (MD) ${ }^{3}$ \\ ${ }^{1}$ Women's Health and Action Research Centre, Km11, Benin-Lagos Expressway, Igue-Iheya, Benin City. Nigeria \\ ${ }^{2}$ Women's Health and Action Research Centre, Km11, Benin-Lagos Expressway, Igue-Iheya, Benin City. Nigeria \\ ${ }^{3}$ Hospitals Management Board, Asaba, Delta State, Nigeria
}

\begin{abstract}
High body mass index has been reported to have several health conditions on indivuals and lowers self-esteem as well as has negative consequences on the cognitive and social development of a person. On a broad view, obesity is a prominent yet preventable cause of death and its prevalence both in children and adults is on the increase. In relation to men, women have a relatively higher burden of disease attributable to overweight and obesity. This study examined the inter-relationship between the socio-economic status and body mass index among women of reproductive age in Nigeria. The study was a cross-sectional design and utilized 2013 Nigeria Demographic Health and Survey dataset. The Nationally representative sample of 38,948 women in all selected households represented a response rate of $98 \%$ of women. The sample design for the $2013 \mathrm{NDHS}$ provides estimates at the national level, urban-rural areas, for each of the six zones, for each of the 36 states, and the Federal Capital Territory (FCT). Data were analyzed using STATA Software version 12.0. Summary statistics, analysis of variance and analysis of covariance were conducted. p-value of $<0.05$ was considered statistically significant. This study clearly revealed that wealth is directly proportional to the BMI of the women of reproductive age in Nigeria. Richest women of reproductive age in Nigeria had highest BMI and vis-à-vis the poorest women. Age was found to be a significant confounder. This study also interestingly revealed that the women living in the southern regions of Nigeria have significantly higher body mass index values than those living in the Northern part of the country. Although, at the $90^{\text {th }}$ quintile, the south-west was found to have the highest BMI value, the south-south has the highest BMI value on the average with the north-east having the lowest BMI value. There is need to enlighten women of reproductive age specifically of high socio-economic status on the implication of high body mass index and how it relates to health and disease occurrence.
\end{abstract}

Keywords: Wealth Index, BMI, ANCOVA, Obesity

\section{Introduction}

Body mass index is an approach to measure the amount of tissue mass (bone, fat and muscle) of an individual. Body mass index values are interpreted as underweight, normal weight, overweight, or obese based [1]. High body mass index (obesity) is a non-communicable medical condition whereby excess body fat accumulate to the extent that it can result to health effects, leading to sudden death, cancer, increased chances of heart disease, diabetes and osteoarthritis [2]. It is assessed by an outcome of measuring the patient for weight and height. The weight (W) in kilograms over height $(\mathrm{h})$ in meters ${ }^{2}\left(\mathrm{~h}^{2}\right)$ gives an index referred to as body mass index (BMI). The measure of extreme BMI to the right is used to differentiate classes of high BMI in patients. A person with a BMI of $<18.5$ is underweight, 18.5 to 24.9 is said to be normal and 25 to 29.9 is overweight and obesity are identified with BMI of $\geq 30$ according to current classification [3] [4]. However, the above outline of obesity does not separate between overweight due to obesity and muscle hypertrophy. Also, although obesity is an index of weight relative to height that is used to classify overweight and obesity in adults, it may not correspond to the same degree of fatness in different individuals [5]. BMI is the most useful population-level measure of overweight and obesity as it is the same for both sexes and for all ages of adults. In addition, it has been reported that body mass index underestimates obesity especially in women having high leptin levels $(>30 \mathrm{ng} / \mathrm{mL})$, since the accuracy can be improved by using the revised leptin levels to estimate body fat proportion when dualenergy x-ray absorptiometry (DEXA) is available [6] Obesity and overweight are known to be among the leading causes of global deaths as documented by the world health organisation.

Report has shown that overweight and obesity have been estimated to cause about 2.6 million deaths worldwide and about $2.5 \%$ of the global burden of diseases [7] Furthermore, it was reported in 2010 that WHO estimated about 350 million adults who were obese, while about 1 billion were overweight, with higher rates for both conditions among women than men [8]. This health condition was once considered a problem of rich countries; but presently obesity rates are increasing worldwide, with developing countries experiencing unprecedented increase a new word describing the global nature of the epidemic has been coined "globesity"[9].

Regionally, the United States has the highest rates of obesity among developed countries at (32\%), in the adult population [10]. The rates vary widely with gender and ethnicity. It is higher in women $35 \%$ than men $33 \%$. More so it was also interesting to note that the scourge is higher among AfricanAmericans than other races [10]. In Canada, the aboriginals tend to be more obese than the Caucasian groups. Due to the dramatic rise in obesity, more than $30 \%$ of annual deaths in 


\section{International Journal of Science and Research (IJSR) \\ ISSN (Online): 2319-7064}

Index Copernicus Value (2013): 6.14 | Impact Factor (2015): 6.391

the US are reported to be associated with obesity related illhealth complications [10].

In South Africa, black women had the highest prevalence of overweight and obesity which was about $58.5 \%$, followed by women of mixed ancestry (52\%), also white women (49.2\%) and Indian women (42.8\%)[11]. More so, studies have revealed that urban women had higher BMI than their rural counterparts and in both groups, BMI increased with age. Central obesity (defined by cut-off points for waist to hip ratio of 0.85 for women and 1.0 for men) was higher among urban African women (42\%) and was most prevalent in African women and among women of mixed race [11].

In India, China, Bangladesh, Indonesia and Japan are listed among the WHO's 10 countries with the greatest prevalence of obesity. In India, morbid obesity in the 21 st century has reached about $5 \%$ of the country's population, while in Chinese cities; about $12 \%$ of adults and $8 \%$ of children were reported obese [10]. Also importantly to note that in West Africa, the rate of obesity is about $10 \%$. It is 3 times higher among women than men. In parts of West Africa, the rates have more than doubled in the last 15 years [10].

In Nigeria, it is estimated that about $6-8 \%$ of the population is obese [12]. It is opined that the increasing consumption of processed and high fat fast foods, frequent snacking while watching movies and lack of regular exercise are contributing to the rise of the scourge. The prevalence of obesity in select African countries as reported was 13, 14 and 15\% in Sudan, Egypt and Libya (North Africa), 15, 10 and $9 \%$ in Ghana, Senegal and Niger (West Africa), and 13, 12 and $14 \%$, respectively, in Kenya, Uganda and Tanzania in East Africa [13].

Evidence from studies conducted in high income countries show a socio-economic gradient in obesity. The prevalence of obesity is shown to be mainly concentrated in people of high socioeconomic status [14], probably because socioeconomic status influences energy intake and expenditure, and thus body fat [15]. Obesity is also found to be proportionately high in economically advantaged women. Hence, the degree of income-related inequalities is on the increase in both men and women [16][17][18]. It was also interesting to note in a study conducted by Hajizadeh et al [19] on the application of concentration index (CI) however reported wealth index-related inequalities in obesity risk Canada population. His finding revealed that obesity was concentrated in rich men and economically disadvantaged women, and the degree of socioeconomic related inequalities was reducing over time. In a related study in Sweden on trend in income-related inequalities in obesity, and showed that obesity inequality we concentrated among the rich [20][17]. It is the light of the above that this study is focused to determine the inter-relationship between wealth index and body mass index among women of reproductive age in Nigeria.

\section{Objectives}

1) To examine the covariance between wealth index and body mass index among women of reproductive age in Nigeria controlling for age (years).
2) To explore the distribution of body mass index among women of reproductive age across geopolitical zones in Nigeria.

\section{Analysis of Covariance (ANCOVA)}

A deficiency with the analysis of variance (ANOVA) is that the differences among groups may be due to other factors that could not be controlled. A proper analysis would need to account for the possible effect of other features. For simplicity, I considered an analysis that accounted, or adjusted, for the effect of women's body mass index when assessing the effect of wealth index.

Let $\mathrm{BMI}_{i j}$ be the body mass index (BMI) for the $j^{\text {th }}$ woman in wealth index group $i(i=1,2,3, \ldots, \mathrm{k})$ with $\mathrm{AGE}_{i j}$. The statistical technique for comparing BMI across wealth index groups, adjusting for women's, is called the analysis of covariance (ANCOVA), and is based on the model:

$$
B M_{i j}=\mu+\alpha_{i}+\beta a g e_{i j}+\varepsilon_{i j}
$$

Where; $\mu$ is a grand mean

$\boldsymbol{\alpha}_{i}$ is the $i^{\text {th }}$ group effect, and $\boldsymbol{\beta}$ is a regression effect.

If $\beta=0$; this is the standard one-way ANOVA model for comparing weights across smoking groups [21]. In words: BMI $=$ Grand Mean + Group Effect + Age Effect + Residual

The ANCOVA model implies that the relationship between the BMI and AGE is linear in each wealth index group, but that the regression lines for the wealth index groups have different intercepts (and equal slopes). The intercept for group $i$ is $\mu+\alpha_{i}$. ANCOVA is a hybrid of ANOVA and Regression.

To better understand why ANCOVA is preferred to the oneway ANOVA on BMI, suppose for argument's sake that $\mathrm{BMI}$ is strongly positively related to AGE. If wealth index is strongly related to AGE, then differences in the BMI for the wealth index groups could be due solely to differences in AGE.

\section{Methods}

The study was based on data of the 2013 Nigeria Demographic and Health Survey (NDHS), implemented by the National Population Commission (NPC). ICF International provided financial and technical assistance for the survey through USAID-funded MEASURE DHS program, which is designed to assist developing countries to collect data on fertility, family planning, and maternal and child health. Financial support for the survey was provided by USAID, the United Kingdom Department for International Development (DFID) through PATHS2, and the United Nations Population Fund (UNFPA).

\section{Study Design and Population}

The study was a cross-sectional design and utilized 2013 Nigeria Demographic Health and Survey dataset. National representative sample of 38,948 women selected from 


\section{International Journal of Science and Research (IJSR) \\ ISSN (Online): 2319-7064 \\ Index Copernicus Value (2013): 6.14 | Impact Factor (2015): 6.391}

households which represented a response rate of $98 \%$ was considered. The sample design for the 2013 NDHS provides estimates at the national level, urban-rural areas, for each of the six zones, for each of the 36 states, and the Federal Capital Territory (FCT).

The 2013 Nigeria Demographic and Health Survey (NDHS) were designed to provide data for monitoring the population and health situation in Nigeria. The 2013 NDHS is the fifth (latest) Demographic and Health Survey conducted in Nigeria since 1990. The objective of the survey was to provide up-to-date information on fertility levels, marriage, fertility preferences, awareness and use of family planning methods, child feeding practices, nutritional status of women and children, adult and childhood mortality, awareness and attitudes regarding HIV/AIDS, and domestic violence. This information is intended to assist policymakers and programme managers in evaluating and designing programmes and strategies for improving health services in the country.

The survey was designed to allow reliable estimation of most variables for a variety of health and demographic analyses at the various domains of interest. For subgroup analysis, the survey also provides estimates with acceptable precision for important population characteristics such as fertility, contraceptive prevalence and other selected health indicators.

NIGERIA

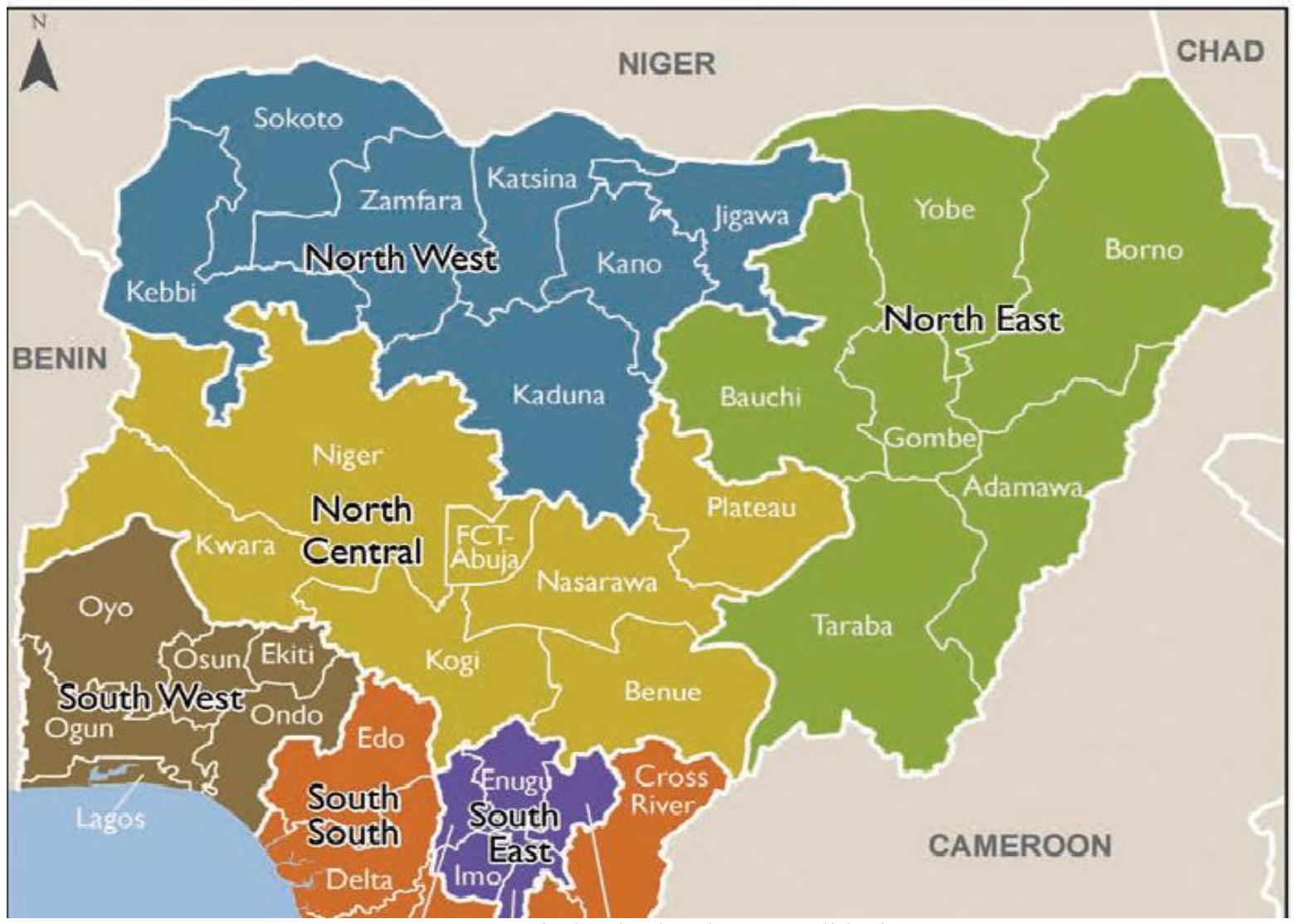

Figure 1: Map of Nigeria showing geopolitical zones

\section{Ethical Clearance}

The DHS Program maintains strict standards for protecting the privacy of all participants. Before each interview, interviewers read out an informed consent statement and mentioned that participation is voluntary and respondent has the liberty to terminate the interview at any point. In addition, the ICF International ensures that the survey complies with the U.S. Department of Health and Human Services regulations for the protection of human subjects, and the host country ensures that the survey complies with laws and norms of the nation. Approval for this study was not required since the data is secondary and is available in the public domain.

\section{Data Analysis}

Summary statistics, analysis of variance and analysis of covariance were conducted. Data were analyzed using
STATA Software version 12.0. $p$-value of $<0.05$ was considered statistically significant.

\section{Results}

Bivariate analysis between age (years) and body mass index $(\gamma=0.3, p<0.001)$ revealed that as age increases, body mass index also increases. This showed that older women had higher body mass index. Form table 1 , it is easy to see that mean body mass index increases by level of wealth index. This showed that as economic status increases, women are more prone to the risk of higher body mass index. In addition, body mass index quintiles revealed same trends of increased mean body mass index across levels of wealth index.

\section{Volume 5 Issue 9, September 2016}




\section{International Journal of Science and Research (IJSR) \\ ISSN (Online): 2319-7064 \\ Index Copernicus Value (2013): 6.14 | Impact Factor (2015): 6.391}

Table 1: Summary statistics of wealth Index level and body mass index

\begin{tabular}{|c|c|c|c|c|c|c|c|}
\hline Wealth & Mean BMI & \multicolumn{7}{|c|}{ BMI Quintiles } \\
\cline { 3 - 8 } Index & & 10 & 25 & 50 & 75 & 90 & $N$ \\
\hline Poorest & $21.77 \pm 6.04$ & 17.78 & 19.27 & 21.04 & 23.15 & 25.37 & 6490 \\
\hline Poorer & $22.02 \pm 3.92$ & 18.12 & 19.69 & 21.52 & 23.67 & 26.27 & 7402 \\
\hline Middle & $22.87 \pm 5.42$ & 18.46 & 20.02 & 21.99 & 24.61 & 27.80 & 7883 \\
\hline Richer & $23.69 \pm 5.28$ & 18.71 & 20.41 & 22.78 & 25.85 & 29.64 & 8369 \\
\hline Richest & $25.23 \pm 6.27$ & 19.32 & 21.28 & 24.11 & 28.00 & 32.34 & 8261 \\
\hline Total & $23.21 \pm 5.59$ & 18.44 & 20.07 & 22.23 & 25.07 & 28.87 & 38405 \\
\hline
\end{tabular}

From table 2, result of the analysis of variance revealed those mean body mass indexes were different across levels of wealth index. The means were not all equal and hence there was need to control for the effect of age with analysis of covariance technique.

Table 2: Analysis of variance for body mass index among women of reproductive age across wealth index level

\begin{tabular}{|c|c|c|c|c|c|}
\hline Source & $S S$ & $D f$ & $M S$ & $F$ & Prod $>F$ \\
\hline $\begin{array}{c}\text { Between } \\
\text { groups }\end{array}$ & 605829859 & 4 & 151457464.823 & 509.767 & $<0.001^{* * *}$ \\
\hline $\begin{array}{c}\text { Within } \\
\text { groups }\end{array}$ & $\begin{array}{c}1.1409 \\
\mathrm{e}+10\end{array}$ & 38400 & 297111.090 & - & - \\
\hline Total & $1.2014 \mathrm{e}+10$ & 38404 & - & - & - \\
\hline
\end{tabular}

$* * * \mathrm{P}<0.05$
Table 3 revealed that economic status (wealth index) is a significant factor $(p<0.001)$ in predicting body mass index of women in reproductive age 15-49years. Similarly, when age (years) was adjusted for in the model, it was found to be a significant factor in predicting the body mass index of women of reproductive age (15-49years) in Nigeria.

Table 3: Analysis of covariance for body mass index and wealth index level adjusting for age (years)

\begin{tabular}{|c|c|c|c|c|c|}
\hline Source & Partial SS & $D f$ & $M S$ & $F$ & Prod $>F$ \\
\hline Model & $1.2151 \mathrm{e}+09$ & 5 & 243021288 & 223.39 & $<0.001^{* * *}$ \\
\hline Wealth Index & 531419149 & 4 & 132854787 & 122.12 & $<0.001^{* * *}$ \\
\hline Age & 686189955 & 1 & 686189955 & 630.75 & $<0.001^{* * *}$ \\
\hline Residual & $4.2365 \mathrm{e}+10$ & 38942 & 1087900.19 & - & - \\
\hline Total & $4.3580 \mathrm{e}+10$ & 38947 & 1118959.5 & - & - \\
\hline
\end{tabular}

Adjusted R-squared $=0.0278 ;$ R-squared $=0.0279$;

$* * * \mathrm{P}<0.05$

Interaction of wealth index and age became significant $(p<0.001)$ in the model as showed in table 4. Adjusted coefficient of determination became higher that the model without interaction, which showed that the addition of the interaction term improved the model's goodness-of-fit (a measure of the predictive power of the model). Similarly, age (years) and wealth index remained significant in the model for the response variable.

Table 4: Interactions in the analysis of covariance for body mass index across wealth index level adjusting for age (years)

\begin{tabular}{|c|l|c|c|c|c|}
\hline Source & Partial SS & Df & MS & F & Prod $>$ F \\
\hline Model & $1.4129 \mathrm{e}+09$ & 9 & 156984788 & 144.96 & $<0.001^{* * *}$ \\
\hline Wealth Index & 43084589.2 & 4 & 10771147.3 & 9.95 & $<0.001^{* * *}$ \\
\hline Age & 654681656 & 1 & 654681656 & 604.54 & $<0.001^{* * *}$ \\
\hline Wealth Index*Age(years) & 197756652 & 4 & 49439163.1 & 45.65 & $<0.001^{* * *}$ \\
\hline Residual & $4.2167 \mathrm{e}+10$ & 38938 & 1082933.19 & - & - \\
\hline Total & $4.3580 \mathrm{e} 10$ & 38947 & 1118959.5 & - & - \\
\hline
\end{tabular}

Adjusted R-squared $=0.032 ; \mathrm{R}$-squared $=0.0324 ; * * * \mathrm{P}<0.05$

Based on the results from table 5, women of reproductive age (15-49years) from South-South and South-West geopolitical zones (region) had mean elevated body mass index. However, women of reproductive age from NorthEast and North-West had lowest mean body mass index.
Table 5: Summary statistics of body mass index for women of reproductive age (15-49years) in different geopolitical

$$
\text { zones }
$$

\begin{tabular}{|c|c|c|c|c|c|c|c|}
\hline \multirow{2}{*}{ Region } & \multirow{2}{*}{ Mean BMI } & \multicolumn{7}{|c|}{ Quintiles } \\
\cline { 3 - 8 } & & $\mathbf{1 0}$ & $\mathbf{2 5}$ & $\mathbf{5 0}$ & $\mathbf{7 5}$ & $\mathbf{9 0}$ & $\mathbf{N}$ \\
\hline NE & $22.46 \pm 5.26$ & 17.92 & 19.51 & 21.68 & 24.23 & 27.62 & 6479 \\
\hline NC & $23.65 \pm 4.68$ & 19.07 & 20.62 & 22.65 & 25.64 & 29.45 & 6180 \\
\hline NW & $22.16 \pm 5.97$ & 17.87 & 19.54 & 21.37 & 23.59 & 26.41 & 9550 \\
\hline SW & $24.00 \pm 5.68$ & 18.62 & 20.34 & 22.84 & 26.39 & 30.79 & 5832 \\
\hline SE & $23.80 \pm 5.59$ & 18.92 & 20.50 & 22.71 & 25.78 & 29.79 & 4389 \\
\hline SS & $24.03 \pm 5.75$ & 19.00 & 20.65 & 23.07 & 26.15 & 30.00 & 5975 \\
\hline Total & $23.21 \pm 5.59$ & 18.44 & 20.07 & 22.23 & 25.07 & 28.87 & $\mathbf{3 8 4 0 5}$ \\
\hline
\end{tabular}

$\mathrm{NE}=$ North East, $\mathrm{NC}=$ North Central, NW= North West, $\mathrm{SW}=$ South West, $\mathrm{SE}=$ South East, $\mathrm{SS}=$ South South.

Table 6 revealed that at least two geopolitical zones had unequal means $(p<0.001)$ in body mass index among women of reproductive age (15-49). Based on this result, we can say that the body mass index of women of reproductive age, to a large extent depended on the region where the women hail from.

Table 6: Analysis of variance for body mass index among women of reproductive age across geopolitical zones in Nigeria

\begin{tabular}{|c|c|c|c|c|c|}
\hline Source & SS & Df & MS & F & Prod $>$ F \\
\hline Between groups & 244461416.249 & 5 & 48892283.250 & 159.503 & $<0.001^{* * *}$ \\
\hline Within groups & $1.1770 \mathrm{e}+10$ & 38399 & 306529.709 & - & - \\
\hline Total & $1.2014 \mathrm{e}+10$ & 38404 & - & - & - \\
\hline
\end{tabular}

Volume 5 Issue 9, September 2016 www.ijsr.net

Licensed Under Creative Commons Attribution CC BY 


\section{International Journal of Science and Research (IJSR) \\ ISSN (Online): 2319-7064 \\ Index Copernicus Value (2013): 6.14 | Impact Factor (2015): 6.391}

\section{Discussion}

The objective of the study was to examine the covariance between wealth index and body mass index among women of reproductive age in Nigeria controlling for age (years), and secondly to explore the distribution of body mass index among women of reproductive age across geopolitical zones in Nigeria using the NDHS 2013 data. As matter of fact it was interesting to note that there was variation in the mean BMI with respect to their wealth index of women of reproductive age in Nigeria. However, evidence from the study revealed that women of high socio economic class have a higher BMI when compare with women of the lower class. This was as also confirmed by the distribution in the summary statistics. To establish this fact we went further to do an ANOVA test of statistics. Evidence revealed that Mean BMI is associated with wealth index with a significance $\mathrm{P}<0.001$ [22].

In addressing the first objective it is interesting to note that Wealth index is a predictor of BMI among women of reproductive age in Nigeria as revealed by the study. The high socioeconomic class has more money to live exorbitant and sedentary life style, which is a predisposing factor to BMI. This fact is not far from already existing [23]. It was also very important to note that age was also a determinant of BMI among women of reproductive age in Nigeria with significance at $\mathrm{P}<0.001$ as seen in Table 3 [24]. Further analysis was done to establish the relationship between age and body mass index in making sure that the relationship is not confounding. Finding revealed a high level of significance at $\mathrm{P}<0.001$ this simply signifies that age is a predictor of BMI among women of reproductive age in Nigeria [25].

The distribution of BMI among geopolitical zone was as assessed in this study. Outcome however reported a different in mean BMI among women of reproductive age in different geopolitical zones in Nigeria. It was noteworthy in the study that women in the south west and south south has the highest BMI followed by north central and south east with north east and north west accounting for the lowest BMI among women of reproductive age in Nigeria. In establishing this fact ANOVA test was done compare the mean between groups. Outcome however revealed that women in the various geopolitical zones have different BMI [26].

\section{Strengths and Limitations}

This study has become one of the foremost in Nigeria to reveal the inter-relationship between wealth index and body mass index and comprised large dataset representing the entire country. However, there are few drawbacks; omission of relevant variables is the most common limitation. DHS do not always report availability, utilization and frequency of utilization of health services and health care delivery as well as health services accessibility which could affect the outcome of interest.

\section{Conclusion}

This study clearly reveals that wealth is directly proportional to the BMI of the women of reproductive age in Nigeria.
Richer women of reproductive age in Nigeria have greater BMI and vis-a-vis. Age was also found to be a significant cofactor for having a greater BMI. Older women within each wealth group had higher BMI values.

This study also interestingly revealed that the women living in the southern regions of Nigeria have significantly higher body mass index values than those living in the Northern part of the country. Although, at the $90^{\text {th }}$ quintile, the southwest was found to have the highest BMI value, the southsouth has the highest BMI value on the average with the north-east having the lowest BMI value.

These findings mean that women of reproductive age are wealthier in the south-south and south-west regions of the country while the poorest women of reproductive age are in the north-east.

\section{Implications of the Study}

There is need to enlighten wealthy women of reproductive age specifically in the southern part of Nigeria on the implication of high body mass index and how it relates to health and disease occurrence. This can help reduce high body mass index (obesity) associated problems such as infertility and some complications in pregnancy, as well as the disease burden of body mass index associated diseases such as hypertension, diabetes and cardiovascular diseases especially in the older age group.

There is also need to address poverty in the country especially north eastern and north western part of the country since the poorest women of reproductive age were found in these regions; and their body mass index in the $10^{\text {th }}$ quintile was below normal (18) which could adversely affect their health as well as increase maternal complications, low birth weights and other maternal and child health challenges especially under five.

\section{Acknowledgement}

I, Ekholuenetale on behalf of other authors, wholeheartedly appreciate Professor Sanni Yaya of University of Ottawa, Canada, for his mentoring role in building my research capability. God bless you richly Sir.

\section{References}

[1] Malcolm Kendrick. "Why being 'overweight' means you live longer: The way scientists twist the facts". http://www.independent.co.uk. (April 12, 2015) Retrieved 12 April 2015.

[2] Anate M, Olatinwo AW, Omesina AP. Obesity an overview. West Afr J Med 1998;17:248-54.

[3] CDC. Prevalence of obesity (class I, II and III) among adults aged $\geq 20$ years, by age group, and sex. National Health and Nutrition Examination Survey (US, $2007-$ 2008), 2010. Found at http://www.cdc.gov/mmwr/preview/mmwr.html/mm591 7a9.htm. Accessed on 30th May, 2012. 2.

[4] Seidell J Assessing obesity: classification and epidemiology. Br. Med. Bull. 1997: 238-252. 


\section{International Journal of Science and Research (IJSR) \\ ISSN (Online): 2319-7064 \\ Index Copernicus Value (2013): 6.14 | Impact Factor (2015): 6.391}

[5] Azinge EC. Obesity and its complications in 30 Nigerian patients in Lagos. Niger Qt J Hosp Med 1997;7:49-52.

[6] Oyekan AO. Genetics of food intake, body weight and obesity-role of Leptin. Niger Med Pract 2005;47:10812.

[7] Klein S, Allison DB, Heymsfield SB, et al. Waist circumference and cardiometabolic risk: a consensus statement from Shaping America's Health: Association for Weight Management and Obesity Prevention; NAASO, The Obesity Society; the American Society for Nutrition; and the American Diabetes Association. Am J Clin Nutr. 2007;85:1197-1202

[8] Abdulbari B. Prevalence of obesity, overweight, and underweight in Qatari adolescents. Food Nutr Bull 2006;27:39-45

[9] Clark DO, Mungai SM. Distribution and association of chronic disease and mobility across four body mass index categories of African-American women. Am J Epidemiol1997;145:865-75.

[10]Luke A, Darazo-Arvizu R, Rotimi C, Prewitt TE, Forrester T,Ogunbiyi OJ, et al. Relation between Body Mass Index and Body Fat in Black Population Samples from Nigeria, Jamaica, and the United States. Am J Epidemiol 1997;145:620-8.

[11] Wardle J, Johnson F. Weight and dieting: Examining levels of concern in British adults. Int $\mathrm{J}$ Obesit 2002;26:1144-9.

[12] Ogunbode AM, Ladipo M, Ajayi IO,Fatiregun AA. Obesity: An emerging disease. Niger J Clin Pract 2011;14:390-4.

[13] Sahyoun NR, Hochberg MC, Helmick CG, Harris T, Pamuk ER. Body mass index, weight change, and incidence of self-reported physician diagnosed arthritis. Am J Pub Health 1999:89:391-4.

[14]Zhang, Q.; Wang, Y. Using concentration index to study changes in socio-economic inequality of overweight among US adolescents between 1971 and 2002. Int. J. Epidemiol. 2007, 36, 916-925. 16.

[15] Brennan, S.L.; Henry, M.J.; Nicholson, G.C.; Kotowicz, M.A.; Pasco, J.A. Socioeconomic status and risk factors for obesity and metabolic disorders in a populationbased sample of adult females. Prev. Med. 2009, 49, 165-171. 18.

[16] Nikolaou, A.; Nikolaou, D. Income-related inequality in the distribution of obesity among Europeans. J. Public Health 2008, 16, 403-411. 19.

[17] Olufunke Alaba and Lumbwe Chola. Socioeconomic Inequalities in Adult Obesity Prevalence in South Africa: A Decomposition Analysis: International Journal of Environmental Research and Public Health. 2014.

[18] Markwick, A.; Vaughan, L.; Ansari, Z. Opposing socioeconomic gradients in overweight and obese adults. Aust. N. Z. Publ. Health, 2013. 37, 32-38. 17.

[19] Hajizadeh, M.; Campbell, M.K.; Sarma, S. Socioeconomic inequalities in adult obesity risk in Canada: Trends and decomposition analyses. Euro. J. Health Econ. 2014, 3, 203-221. 20.

[20] Ljungvall, A.; Gerdtham, U.G. More equal but heavier: A longitudinal analysis of income-related obesity inequalities in an adult Swedish cohort. Soc. Sci. Med. 2010, 70, 221-231.
[21] Montgomery, Douglas C. "Design and analysis of experiments" (8th Ed.). John Wiley \& Sons, 2012.

[22] National Task Force on the Prevention and Treatment of Obesity. Medical Care for Obese Patients: Advice for Health Care Professionals. Am Fam Physician 2002; 65:81-8.

[23] Pi-Sunyer FX. Comorbidities of overweight and obesity: Current evidence and research issues. Med Sci Sports Exerc 1999;31(Supp 1):S602-8.

[24] Swinburn B, Ashton T, Gillespie J, Cox B, Menon A, Simmons D,et al. Healthcare costs of obesity in New Zealand. Int J Obesit Relat Metab Disord 1997;21:8916.

[25] Navadeh, S., Sajadi, L., Mirzazadeh, A., Asgari, F., \& Haghazali, M. Housewives' obesity determinant factors in Iran National Survey - Stepwise approach to surveillance, Iranian journal of Public health, 2011: 40 (2).

[26] Muening, P., Lubetkin, E., Jia, H., \& Franks, P. Gender and the burden of disease attributable to obesity, American Journal of Public Health. 2006: 96 (9) 16621668 . 